NBER WORKING PAPER SERIES

HYPERBOLIC DISCOUNT FUNCTIONS, UNDERSAVING, AND SAVINGS POLICY

David I. Laibson

Working Paper 5635

\author{
NATIONAL BUREAU OF ECONOMIC RESEARCH \\ 1050 Massachusetts Avenue \\ Cambridge, MA 02138 \\ June 1996
}

This work has been supported financially by the National Science Foundation (SBR-95-10985) and the Alfred P. Sloan Foundation. I am grateful to Joshua S. White for excellent research assistance. I have benefitted from conversations with Robert Barro, Roland Benabou, Olivier Blanchard, Casey Mulligan, Richard Zeckhauser and seminar participants at Boston College, Dartmouth, Harvard, Johns Hopkins, Ohio State, NBER, NYU, University of Arizona, and University of Michigan. This paper is part of NBER's research program in Asset Pricing. Any opinions expressed are those of the author and not those of the National Bureau of Economic Research.

(C) 1996 by David I. Laibson. All rights reserved. Short sections of text, not to exceed two paragraphs, may be quoted without explicit permission provided that full credit, including $(\mathcal{O}$ notice, is given to the source. 
NBER Working Paper 5635

June 1996

\title{
HYPERBOLIC DISCOUNT FUNCTIONS, UNDERSAVING, AND SAVINGS POLICY
}

\begin{abstract}
Studies of animal and human behavior suggest that discount functions are approximately hyperbolic (Ainslie, 1992). I analyze an economy with complete markets which is populated by hyperbolic consumers. I identify two ways in which this economy can be distinguished from an exponential economy. First, hyperbolic discounting predicts the empirical regularity that the elasticity of intertemporal substitution is less than the inverse of the coefficient of relative risk aversion. Second, hyperbolic discounting explains many features of the policy debate about undersaving. The calibrated hyperbolic economy matches Bernheim's (1994) survey data on selfreported undersaving, and predicts pro-savings government interventions like capital-income subsidies and penalties for early withdrawal from retirement accounts. Hyperbolic consumers are willing to sacrifice $9 / 10$ of a year's worth of income to induce the government to implement optimal revenue-neutral saving incentives.
\end{abstract}

David I. Laibson

Department of Economics

Harvard University

Littauer M-14

Cambridge, MA 02138

and NBER 


\section{Introduction}

Many governments are currently engaged in a policy debate about savings. This paper contributes to this discussion by developing and calibrating a model which explores the role that self-control problems play in eliciting suboptimal savings levels.

Self-control is an important source of undersaving. Individuals report overwhelmingly that they save much less than they feel they should given the private incentives they face (Bernheim, 1994). This kind of undersaving can not be explained by capital taxation models (Chamley, 1986) or moral hazard models (Hubbard et al, 1995) since these models assume that individuals save optimally conditional on the private incentives they face. For example, a classical economic actor in an economy with inefficiently high capital taxation rates might reason, "If the government lowered the tax rate on capital I would accumulate more capital and I would be better off. But, given the inefficient tax environment that I face, my capital accumulation plans are optimal." By contrast the sophisticated saver in my model would report, "Regardless of which tax regime the goverment adopts, I expect to experience a large gap between my actual saving level and my normative saving level." Analysis of this self-control problem provides a quantitative framework in which to discuss both the normative and positive aspects of savings policy.

The centerpiece of my analysis is the hyperbolic discount function. Research on animal and human behavior has led psychologists to conclude (see Ainslie (1992) and Loewenstein and Prelec (1992)) that discount functions are generalized hyperbolas: events $\tau$ periods away are discounted with factor 
$(1+\alpha \tau)^{-\gamma / \alpha}$, with $\alpha, \gamma>0$. Such discount functions imply a monotonically falling discount rate. This discount structure sets up a conflict between today's preferences and the preferences which will be held in the future, implying that preferences are dynamically inconsistent. For example, from today's perspective, the discount rate between two far off periods, $t$ and $t+1$, is a long-term low discount rate. However, from the time $t$ perspective, the discount rate between $t$ and $t+1$ is a short-term high discount rate. This type of preference "change" is reflected in many common experiences. For example, today I may desire to quit smoking next year, but when next year actually roles around my taste at that time will be to postpone any sacrifices another year.

Hyperbolic discount functions generate a preference structure which is a special case of the general class of dynamically inconsistent preforences: i.e., preferences which imply a conflict between the optimal contingent plan from today's perspective and the optimal decision from tomorrow's perspective. Robert Strotz (1956) was the first economist to study dynamically inconsistent preferences. Pollak (1968), Peleg and Yaari (1973), Goldman (1980), and Schelling (1988) have extended Strotz's work, arguing that when preferences are dynamically inconsistent, dynamic decisions should be modelled as an intra-personal game among different temporal selves (i.e., today's self is modelled as a different player from tomorrow's self).

Despite the availability of this analytic framework, and the substantial body of evidence supporting hyperbolic discounting, few economists have studied the implications of hyperbolic discount functions. ${ }^{2}$ Phelps and Pol-

\footnotetext{
${ }^{2}$ Some economists have explained self-control problems using multiple-self models which
} 
lak (1968) analyze an inter-generational game in which each generation has a discount function which I will argue below proves to be approximately hyperbolic. Zeckhauser and Fels (1968) provide an altrusim-based microfoundation for the Phelps and Pollak preferences. Akerlof (1991) analyzes the behavior of decision-makers who place a special premium on effort made in the current period. Such a premium can be interpreted as a reflection of hyperbolic discounting although Alkerlof interprets these preferences as a salience effect. Akerlof's analysis is inconsistent with the intra-personal game approach as his decision-makers act myopically; they fail to foresee the preference "changes" described above. Loewenstein and Prelec (1992) also analyze the choices of myopic decision-makers with hyperbolic discount functions. Finally, George Ainslie, a psychiatrist, has studied the behavior of sophisticated hyperbolic decision-makers (Ainslie (1992)), although his work is primarily qualitative. My past work (Laibson 1995) and the analysis below formalizes, quantifies, and extends Ainslie's analysis. This paper focusses on the relationship between hyperbolic discount functions, undersaving, and savings policy.

The paper is divided into six sections, including this introduction. Section two lays out the formal model, describing the specific intra-personal game of interest. Section two presents an approximately hyperbolic discount function which includes the standard exponential discount structure as a special case. Section three characterizes the equilibrium path, discusses observational equivalence with an exponential economy, analyzes the relationare not based on hyperbolic discounting .... e.g., Thaler and Shefrin (1981), and Schelling (1984). 
ship between risk aversion and intertemporal substitution, and calibrates the model for consistency with Bernheim's (1994) undersaving results. Section four presents a menu of policies which address the undersaving problem. Section five analyzes the welfare benefits of implementing these policies. Section six concludes.

\section{An individual's consumption problem.}

I model an individual as a composite of autonomous temporal selves, following Strotz (1956), Pollak (1968), Peleg and Yaari (1972), Goldman (1980), and Schelling (1984). These selves are indexed by their respective periods of control, $(t=0,1,2, \ldots, T)$, over a consumption decision. During its period of control, self $t$ observes all past consumption levels $\left(c_{0}, c_{1}, c_{2}, \ldots, c_{t-1}\right)$, and the current level of human and financial wealth $W_{t}$. (The wealth measure, $W_{t}$, represents the sum of current financial wealth and the present value of the stream of labor income.) Self $t$ chooses a consumption level for period $t$, which satisfies the restriction,

$$
0 \leq c_{t} \leq W_{t}
$$

Self $t+1$ then "inherits" wealth equal to,

$$
W_{t+1}=R \cdot\left(W_{t}-c_{t}\right)
$$

where $R$ is the gross real return on wealth, which is assumed to be fixed. ${ }^{3}$ The game continues, with self $t+1$ in control. Finally, note that in this game

\footnotetext{
${ }^{3}$ An earlier version of this paper allowed $R$ to be chosen endogenously. The results proved to be qualitatively and quantitatively little different from the results that arise with a fixed $R$.
} 
the commitment solution discussed by Strotz (1956) is implicitly ruled out; i.e., the current self can not commit future selves to a particular consumption path. From the perspective of the time zero self, commitment would be optimal. However, commitment may not be possible. The capacity to commit depends on the contracting environment. If contracts are written at period zero and there exist no opportunities to write new contracts (or spot markets on which to trade contractual obligations), then commitment is possible. By contrast, if contracts can be renegotiated or traded in spot markets commitment will not be possible. Commitments I make today will be renegotiated by future selves who wish to undo those commitments. Moreover, commitments can be unwound using third parties. For example, if I give all my assets to bank $\mathrm{A}$ and instruct it to make payments to me on an annuity basis, my future selves can use that stream of payments as collateral to borrow from bank $\mathrm{B}$, thereby undoing my initial commitment. With considerations like this in mind, commitment is effectively impossible, motivating the absence of commitment in the model.

Now it only remains to specify the payoffs of the "players" of this game. Player $t$ receives payoff

$$
U_{t}\left(c_{0}, c_{1}, \ldots, c_{T}\right)=E_{t}\left[u\left(c_{t}\right)+\beta \sum_{i=1}^{T-t} \delta^{i} u\left(c_{t+i}\right)\right]
$$

where $\delta$ and $\beta$ are discount parameters, and $u(c)$ is a member of the class of CRRA utility functions (with relative risk aversion coefficient $\rho \in(0, \infty)$ ):

$$
u(c)=\frac{c^{1-\rho}-1}{1-\rho} .
$$

There are two reasons to focus on the preferences in equation 3 . The first motivation is that if $u$ is in the CRRA class and $\beta=1$, the model reduces to 
the familiar case of exponential discounting with time-additive homothetic preferences. Hence the $\beta \neq 1$ case may be thought of as a perturbation to the "standard" preferences used in macroeconomic models. If we care about robustness we probably want to know what happens when such perturbed preferences are considered.

The second motivation is more important. There is a large body of evidence that discount functions are closely approximated by generalized hyperbolas: events $\tau$ periods away are discounted with factor $(1+\alpha \tau)^{-\gamma / \alpha}$, with $\alpha, \gamma>0{ }^{4}$ This observation was first made by Chung and Herrnstein (1961) in relation to animal behavior experiments. ${ }^{5}$ Their conclusions were later shown to apply to human subjects as well (see Ainslie (1992) for a survey).

Hyperbolic discount functions imply discount rates that decline as the discounted event is moved further away in time (Loewenstein and Prelec, 1992). Events in the near future are discounted at a higher implicit discount rate then events in the distant future.

Given a discount function, $f(\tau)$, the instantaneous discount rate at time $\tau$ is defined as,

$$
\frac{-f^{\prime}(\tau)}{f(\tau)}
$$

Hence, an exponential discount function, $\delta^{\tau}$ is characterized by a constant discount rate, $\log \left(\frac{1}{\delta}\right)$, while the generalized hyperbolic discount function is

\footnotetext{
${ }^{4}$ See Loewenstein and Prelec (1992) for an axiomatic derivation of this discount function.

${ }^{5}$ Chung and Herrnstein claimed that the appropriate discount function is an exact hyperbola: events $\tau$ periods away are discounted with factor $\frac{1}{\tau}$. This corresponds to the limiting case $\alpha=\gamma \rightarrow \infty$.
} 
characterized by an instantaneous discount rate that falls as $\tau$ rises:

$$
\frac{\gamma}{1+\alpha \tau}
$$

Psychologists and economists -.- notably Ainslie (1975, 1986, 1992), Prelec (1989), and Loewenstein and Prelec (1992) - believe that such declining discount rates play an important role in generating problems of self-regulation.

When $0<\beta<1$ the discount structure in Equation 3 mimics the qualitative property of the hyperbolic discount function, while maintaining most of the analytical tractibility of the exponential discount function. I call the discount structure in Equation 3 "quasi-hyperbolic." Note that the quasi-hyperbolic discount function is a discrete time function with values $\left\{1, \beta \delta, \beta \delta^{2}, \beta \delta^{3}, \ldots\right\}$. Figure 1 graphs the exponential discount function (assuming $\delta=.97$,), the generalized hyperbolic discount function (assuming $\alpha=10^{5}$, and $\gamma=5 \cdot 10^{3}$ ), and the quasi-hyperbolic discount function (with $\beta=.6$ and $\delta=.99)$. The points of the discrete-time quasi-hyperbolic function have been connected to generate the smooth curve in Figure 1.

The preferences in Equation 3 were first analyzed by Phelps and Pollak (1968). However, their choice of this structure was motivated in a different way. Their game is one of imperfect intergenerational altruism, so the players are non-overlapping generations of a dynasty. I assume that the different players are temporally distinct selves of a single person. My set-up also differs because I assume the horizon is finite. Phelps and Pollak assume an infinite horizon which admits a continuum of equilibria (Laibson (1994)). 


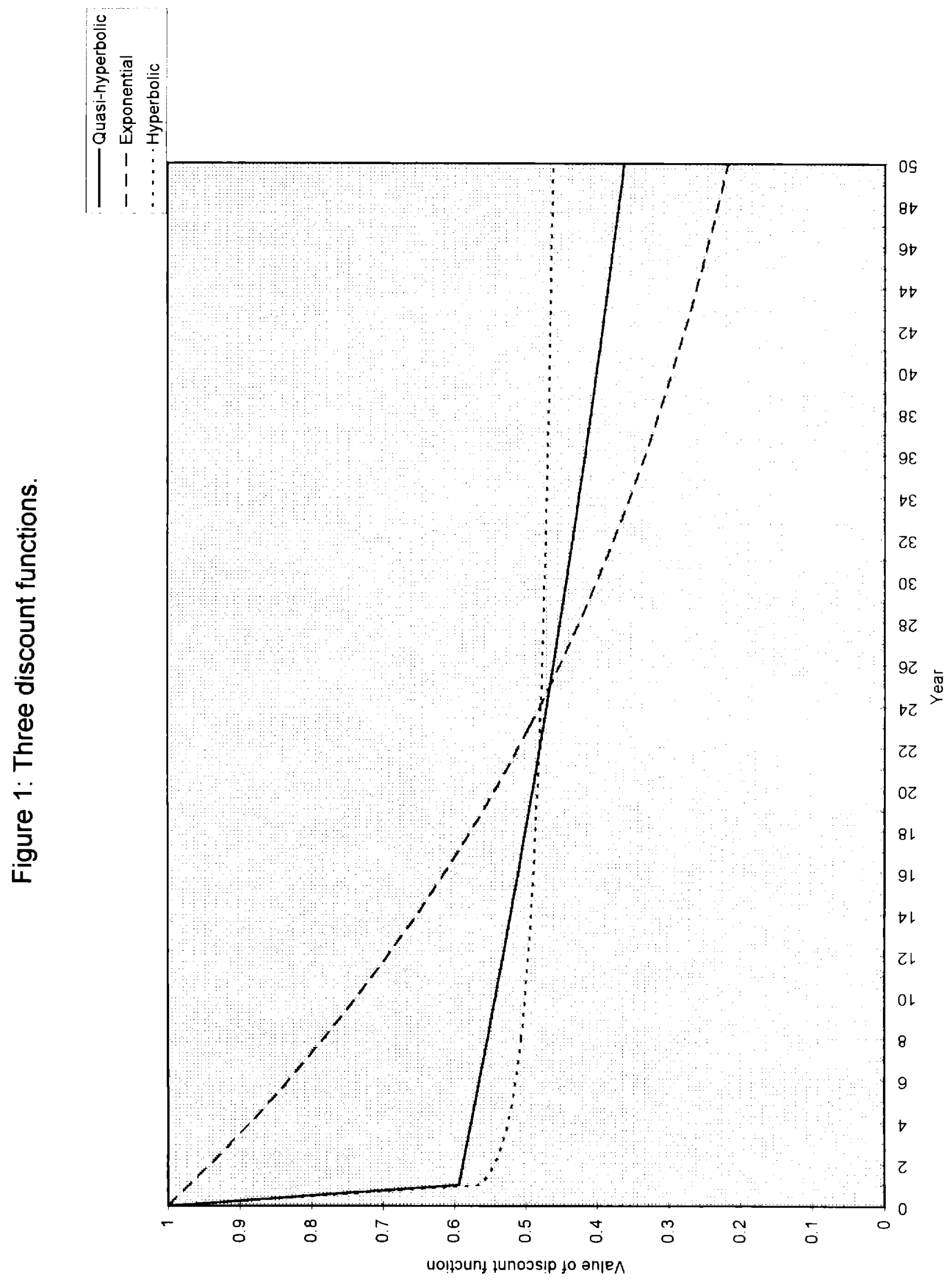




\section{An Euler Equation, Intertemporal Substi- tution, and Undersaving}

\subsection{Equilibrium}

In this subsection, I show that there is a unique subgame perfect equilibrium in the finite-horizon game. I characterize that equilibrium and consider its limiting properties as the horizon goes to infinity.

Proposition 1: For ANy finite-horizon game, there EXISTS A UNIQUE SUBGAME-PERFECT EQUILIBRIUM. THIS EQUILIBRIUM IS MARKOV PERFECT AND IS CHARACTERIZED BY TIME-DEPENDENT CONSUMPTION RULES WHICH ARE LINEAR IN WEALTH. ${ }^{6}$

Proposition 1 is proven by applying a backwards induction argument. (All proofs are consigned to the appendix.) Since the unique subgame perfect equilibrium is a sequence of Markov strategies, we can write the equilibrium strategy of self $t$ in a $T$-horizon game as, $c_{t}\left(W_{t}, T\right)$. Proposition 1 also implies that $c_{t}\left(W_{t}, T\right)$ is differentiable. Using these basic results, it is possible to derive a generalized Euler equation which applies in the hyperbolic economy. The following development is heuristic. Formal propositions follow.

The marginal benefit of postponing $\Delta \approx 0$ units of consumption generates a stream of utility perturbations from the perspective of self $t$. At time $t$,

$$
\Delta \cdot u^{\prime}\left(c_{t}\right)
$$

\footnotetext{
${ }^{6}$ Markov perfect equilibria have the property that equilibrium strategies depend only on payoff-relevant state variables. See Fudenberg and Tirole, chpt. 13, for a formal definition.
} 
utils are lost. At time $t+1$

$$
\beta \cdot \delta \cdot \frac{\partial c_{t+1}}{\partial W_{t+1}} \cdot R \cdot \Delta \cdot u^{\prime}\left(c_{t+1}\right)
$$

utils are gained. Note that $\frac{\partial c_{t+j}}{\partial W_{t+j}}$ is the marginal consumption rate at period $t+j$. At time $\mathrm{t}+2$,

$$
\beta \cdot \delta^{2} \cdot \frac{\partial c_{t+2}}{\partial W_{t+2}} \cdot\left(1-\frac{\partial c_{t+1}}{\partial W_{t+1}}\right) \cdot R^{2} \cdot \Delta \cdot u^{\prime}\left(c_{t+2}\right)
$$

utils are gained, etc .... The net effect sums to,

$$
-\Delta u^{\prime}\left(c_{t}\right)+\beta \sum_{i=1}^{T-t} \delta^{i} \frac{\partial c_{t+i}}{\partial W_{t+i}}\left[\prod_{j=1}^{i-1}\left(1-\frac{\partial c_{t+j}}{\partial W_{t+j}}\right)\right] R^{i} \Delta u^{\prime}\left(c_{t+i}\right) .
$$

Setting this expression equal to zero and dividing by $\Delta$ yields an Euler equation.

$$
u^{\prime}\left(c_{t}\right)=\beta \sum_{i=1}^{T-t} \delta^{i} \frac{\partial c_{t+i}}{\partial W_{t+i}}\left[\prod_{j=1}^{i-1}\left(1-\frac{\partial c_{t+j}}{\partial W_{t+j}}\right)\right] R^{i} u^{\prime}\left(c_{t+i}\right)
$$

Consider the analogous Euler equation for period $t+1$ :

$$
u^{\prime}\left(c_{t+1}\right)=\beta \sum_{i=1}^{T-(t+1)} \delta^{i} \frac{\partial c_{t+1+i}}{\partial W_{t+1+i}}\left[\prod_{j=1}^{i-1}\left(1-\frac{\partial c_{t+1+j}}{\partial W_{t+1+j}}\right)\right] R^{i} u^{\prime}\left(c_{t+1+i}\right)
$$

Substitution of Equation 6 into Equation 5 yields the generalized Euler equation in Proposition 2.

Proposition 2: Consider a T-HORIzon game. The folLOWING EULER EQUATION HOLDS ON THE UNIQUE EQUILIBRIUM PATH.

$$
u^{\prime}\left(c_{t}\right)=R \delta u^{\prime}\left(c_{t+1}\right)\left[\beta \cdot \frac{\partial c_{t+1}\left(W_{t+1}, T\right)}{\partial W_{t+1}}+\left(1-\frac{\partial c_{t+1}\left(W_{t+1}, T\right)}{\partial W_{t+1}}\right)\right]
$$


This equation reduces to the standard Euler Equation when $\beta=1$. When $\beta<1$ the RHS of Equation 7 is greater than $\beta \delta R u^{\prime}\left(c_{t+1}\right)$, as the bracketed term on the RHS of Equation 7 is a weighted average of $\beta<1$ and 1 . Hence the "standard" Euler equation intuition -... on the equilibrium consumption path marginal utility today is equal to the gross interest rate multiplied by discounted marginal utility tomorrow -- does not apply when preferences are dynamically inconsistent. The breakdown of the intuition behind the "standard" Euler equation occurs because on the equilibrium path self $t$ gets more marginal utility from incremental consumption in the distant future than from incremental consumption in the near future. This arises because the "overconsumption" of self $t+1$-- from the perspective of self $t$ - lowers marginal utility at time $t+1$ relative to marginal utility in future periods.

Proposition 3: THE EQUILIBRIUM CONSUMPTION RULE IS: $c_{t}\left(W_{t}, T\right)=\lambda_{T-t} W_{t}$, WHERE THE SEQUENCE $\left\{\lambda_{i}\right\}_{i=0}^{\infty}$ IS GIVEN BY THE RECURSION,

$$
\lambda_{i+1}=\frac{\lambda_{i}}{\left[\delta R^{1-\rho}\left(\lambda_{i}(\beta-1)+1\right)\right]^{\frac{1}{\rho}}+\lambda_{i}},
$$

WITH $\lambda_{0}=1$.

Proposition 4: As $T \rightarrow \infty, c_{t}(W, T)$ CONVERGES POINTWISE TO THE FUNCTION $\lambda^{*} W$, WHERE $\lambda^{*}$ IS THE UNIQUE SOLUTION TO THE NON-LINEAR EQUATION:

$$
\lambda^{*}=1-\left(\delta R^{1-\rho}\right)^{\frac{1}{\rho}}\left[\lambda^{*}(\beta-1)+1\right]^{\frac{1}{\rho}} .
$$


Note that $\lambda^{*}$ is also an equilibrium consumption rate in the infinitehorizon game (Phelps and Pollak (1968)). However, it is not the unique equilibrium consumption rate in that game (Laibson (1994)).

Proposition 3 implies $\frac{\partial c_{t+1}\left(W_{t+1}, T\right)}{\partial W_{t+1}}=\lambda_{T-(t+1)}$. Combining this observation with Proposition 2 implies that the generalized Euler Equation can be expressed as:

$$
u^{\prime}\left(c_{t}\right)=R \delta u^{\prime}\left(c_{t+1}\right)\left[\lambda_{T-(t+1)}(\beta-1)+1\right] .
$$

Proposition 4 implies that as the horizon gets arbitrarily large $(T \rightarrow \infty)$, this generalized Euler Equation converges to

$$
u^{\prime}\left(c_{t}\right)=R \delta u^{\prime}\left(c_{t+1}\right)\left[\lambda^{*}(\beta-1)+1\right]
$$

\subsection{An Observational Equivalence Result}

Equation 11 is closely related to the standard Euler equation in exponential discounting models. Consider an economy populated by consumers with exponential discount factor $\bar{\delta}$. The Euler equation in this economy is:

$$
u^{\prime}\left(c_{t}\right)=R \bar{\delta} u^{\prime}\left(c_{t+1}\right)
$$

Consider the inference problem of a misinformed econometrician. The econometrician lives in the hyperbolic world analyzed above. But the econometrician believes that she is living in the exponential world introduced in this subsection. The econometrician uses the data available to her to infer $\bar{\delta}$. 
She calculates

$$
\bar{\delta}=\frac{u^{\prime}\left(c_{t}\right)}{R u^{\prime}\left(c_{t+1}\right)}=\frac{1}{R} \cdot\left(\frac{c_{t+1}}{c_{t}}\right)^{\rho}
$$

The econometrician will not realize that she is estimating the wrong model, since the hyperbolic world induces a constant value for $\frac{u^{\prime}\left(c_{t}\right)}{R u^{\prime}\left(c_{t+1}\right)}$. For example, if $\rho=3, \beta=.6, \delta=.99$, and $R=\exp \{r\}=\exp \{.04\}$, (and the econometrician independently observes the true $\rho$ and $R$ values), then our econometrician will estimate

$$
\bar{\delta}=\frac{u^{\prime}\left(c_{t}\right)}{R u^{\prime}\left(c_{t+1}\right)}=\delta\left[\lambda^{*}(\beta-1)+1\right]=.977
$$

The second equality in the previous equation follows from Equation 11. The estimated discount factor, $\bar{\delta}=.977$, sharply contrasts with the actual oneperiod discount factor of $\beta \delta=(.6) \cdot(.99)=.59$. The econometrician will radically misconstrue the preferences of the actors that she is observing.

With the exception of my choice of $\beta$--.. which is explained in subsection 3.3 - I chose the parameter values listed above on a priori grounds. The coefficient of relative risk aversion, $\rho$ is usually estimated to lie between 1 and 5 , so I fixed $\rho=3$. Survey respondents are approximately indifferent between reward dates in the distant future, so I fixed $\delta=.99$ (see Barskey et al 1995). In a Cobb-Douglas economy with capital share .36 , capital-income ratio 3 , and depreciation rate .08 , the competitive equilibrium interest rate is $\log R=.04$. These parameter values will be used to generate examples throughout the paper. I refer to this as the benchmark calibration. 


\begin{tabular}{|c||l|c|}
\hline \multicolumn{3}{|c|}{ Benchmark Calibration } \\
\hline \hline$\beta$ & discount parameter & .6 \\
\hline$\delta$ & discount paramteter & .99 \\
\hline$\rho$ & coefficient of relative risk aversion & 3 \\
\hline$R$ & gross interest rate & $\exp \{.04\}$ \\
\hline
\end{tabular}

For readers interested in exploring the implications of choosing other calibration combinations, I have included a series of tables in an appendix. Table 1 presents values of $\bar{\delta}$ associated with a range of calibration choices. For all of these calculations, I assume that the econometrician can independently confirm the true value of $R$ and $\rho$. The technology variable $R$ is set to $\exp \{.04\}$. Calibration values for the preference parameters $\beta$ and $\delta$ are listed in the margins of the table. The table has three pancls, corresponding to $\rho$ values one, three, and five.

The results of this subsection imply that the hyperbolic world with discount parameters $\beta=.6$ and $\delta=.99$ is "observationally equivalent" to the exponential world with discount factor $\bar{\delta}=.977$. In this context observational equivalence means that an econometrician with consumption path data could not determine whether the hyperbolic or exponential economy generated that data. The rest of the paper explores some special properties of the two economies that would enable an economist to tell them apart.

\subsection{Risk aversion and intertemporal substitution.}

So far I have assumed that the economy under study exhibits no variability in interest rates, either across time or across agents. Let's jettison the latter half of this assumption. We can then estimate the elasticity of intertemporal 
substitution (EIS) by measuring how the slope of the consumption path varies as the interest rate $r$ varies. Note that all of this variation is across agents. Assume, for example, that we have a cross-section of countries with different capital taxation policies and hence different after-tax rates of return. ${ }^{7}$

In the standard exponential economy described above, the elasticity of intertemporal substitution is the inverse of the coefficient of relative risk aversion. Specifically,

$$
\mathrm{EIS} \equiv \frac{\partial \log \left(\frac{c_{t+1}}{c_{t}}\right)}{\partial r}=\frac{1}{\rho} .
$$

This well-known theoretical relationship is contradicted weakly by the available empirical evidence (see Hall (1988) and Carroll and Summers (1991)). Most empirical analysis suggests that the EIS is smaller than the inverse of the coefficient of relative risk aversion. ${ }^{8}$ The hyperbolic economy is consistent with this empirical regularity. Using Equation 11 to derive the EIS in the hyperbolic model yields:

$$
\frac{\partial \log \left(\frac{c_{t+1}}{c_{t}}\right)}{\partial r}=\frac{1}{\rho}+\frac{1}{\rho}\left[\frac{1}{\lambda^{*}(\beta-1)+1}\right] \frac{\partial \lambda^{*}}{\partial r}(\beta-1) .
$$

Note that when $\beta=1$ the EIS is equal to $\frac{1}{\rho}$ which is the standard casc described above. However, when $\beta<1$ the one-to-one link between the elasticity of substitution and $\rho$ is broken.

\footnotetext{
${ }^{7}$ The results of this subsection would need to be modified if we identified the EIS off of intertemporal variation in the interest rate, particularly if that variation were characterized by high frequency transitory shifts in the level of the interest rate. By contrast, the results of this subsection would continue to hold if we identified the EIS off of intertemporal variation characterized by relatively persistent changes in the level of the interest rate.

${ }^{8}$ This claim is somewhat controversial. If the coefficient of relative risk aversion is greater than 10 , then the data is consistent with the relationship EIS $=\frac{1}{\rho}$. However, simple thought experiments suggest that risk aversion of that magnitude is problematic (Mankiw and Zeldes, 1991).
} 
The first step in evaluating the EIS is to calculate $\frac{\partial \lambda^{*}}{\partial \tau}$ by totally differentiating Equation 9. Substituting this into Equation 14 yields,

$$
\frac{\partial \log \left(\frac{c_{t+1}}{c_{t}}\right)}{\partial r}=\frac{1}{\rho}+\frac{1}{\rho}\left[\frac{(1-\rho)\left(1-\lambda^{*}\right)}{-(\beta-1)\left(1-\lambda^{*}\right)-\rho\left(\lambda^{*}(\beta-1)+1\right)}\right](\beta-1) .
$$

Note that the numerator and the denominator of the bracketed term are negative if $\rho>1$.

\section{Proposition 5: IN THE HYPERBOLIC MODEL,}

$$
\text { EIS }<\frac{1}{\rho} \quad \text { IF } \quad \rho>1 .
$$

Proposition 6 provides a limiting result on the EIS.

Proposition 6: IF $\rho>1, \lim _{\beta \rightarrow 0}$ EIS $=0$.

Hence, if $\rho>1$, EIS can be made arbitrarily close to zero by choosing a low $\beta$ value. By contrast, in the standard exponential model the EIS is insensitive to changes in the value of the discount function.

Finally, consider the benchmark calibration values introduced in the previous subsection: $\rho=3, \beta=.6, \delta=.99$, and $R=\exp \{r\}=\exp \{.04\}$. Given these parameters, EIS $=.23<\frac{1}{3}=\frac{1}{\rho}$. Table 2 (in Appendix) considers a range of calibration values. Note that Table 2 has two panels, corresponding to $\rho$ values three, and five. Other tables in this paper also include a panel for $\rho=1$. This panel is excluded from Table 2 as $\rho=1$ implies EIS $=1$ (see Equation 15). 


\subsection{Target Savings Rate}

Phelps and Pollak (1968) analyze an economy with identical preferences (although the actors in their economy are generations of a dynasty rather than intra-personal selves). They find that the equilibrium savings rate is Paretodominated by savings rates that are marginally higher. Specifically, all dynastic generations would be made better off if they would all perturb their savings rates up. Equivalently, a multi-self interpretation of these preferences would imply that all selves would be made better off if they would all perturb their savings rates up.

I extend Phelps and Pollak's analysis by asking how big these upward perturbations should be. To do this I consider two normative savings rates for the hyperbolic economy and contrast these savings rates with the equilibrium savings rate.

For large $\mathrm{T}$, the equilibrium savings rate in the hyperbolic economy is

$$
S^{*} \equiv \frac{(R-1)-\lambda^{*} R}{R-1}
$$

Note that income in period $t$ is $(R-1) \cdot W_{t-1}$, and consumption in period $t$ is $\lambda^{*} \cdot R \cdot W_{t-1}$. In this subsection, I compare the savings rate in Equation 16 to two normative definitions of target savings.

Definition I: NoRmative SAVINGS RATE I IS THE LIFETIME SAVINGS RATE TO WHICH SELF 0 WOULD COMMIT ITSELF AND ALL FUTURE SELVES.

Note that choosing a lifetime savings rate is isomorphic to choosing a lifetime consumption rate $\lambda$. Equation 16 implies a one-to-one relationship 
between savings rates and consumption rates. Let

$$
\lambda^{I} \equiv \operatorname{argmax}_{\lambda} u(\lambda W)+\beta \sum_{i=1}^{\infty} \delta^{i} u\left(\lambda(1-\lambda)^{i} R^{i} W\right)
$$

This implies that $\lambda^{I}$ solves the following first order condition:

$$
1+\beta\left[\frac{\delta R^{1-\rho}(1-\lambda)^{1-\rho}}{1-\delta R^{1-\rho}(1-\lambda)^{1-\rho}}\right]-\frac{\beta \lambda}{1-\lambda}\left[\frac{\delta R^{1-\rho}(1-\lambda)^{1-\rho}}{\left[1-\delta R^{1-\rho}(1-\lambda)^{1-\rho}\right]^{2}}\right]=0
$$

By definition, normative savings rate $\mathrm{I}$ is given by:

$$
S^{I} \equiv \frac{(R-1)-\lambda^{I} R}{R-1}
$$

Proposition 7: Normative savings rate I $\left(S^{I}\right)$ IS Greater THAN THE EQUILIBRIUM SAVINGS RATE $\left(S^{*}\right)$. THE CONSUMPTION PATH IMPLIED BY NORMATIVE SAVINGS RATE I PARETODOMINATES THE EQUILIBRIUM CONSUMPTION PATH.

Proposition 7 is formally proved in the Appendix. However, Proposition 7 is easy to understand at an intuitive level. The claim, $S^{I}>S^{*}$, follows from the fact that hyperbolic discount functions imply that self $t$ is more patient about tradeoffs between any two future periods $t+\tau$ and $t+\tau+1$ then is self $t+\tau$. Hence, self $t$ wants to increase self $t+\tau$ 's savings rate relative to what self $t+\tau$ would have saved in the no-commitment equilibrium. The Pareto-dominance result follows from three observations. First, if self $t$ gets to pick a stationary consumption rate for itself and all future selves, than that consumption rate must make it at least as well off as the constant consumption rate, $\lambda^{*}$, which arises in the unique subgame-perfect equilibrium. Second, future solves prefor the stationary consumption rate $\lambda^{I}$ chosen by self $t$ for the same reason that 
self $t$ preferred it. The future selves benefit additionally because they inherit more wealth on the path associated with $\lambda^{I}$ since $\lambda^{I}<\lambda^{*}$.

Below, I consider a second normative savings rate, which turns out to be close in value to normative savings rate I. Normative savings rate II is more analytically tractable than normative savings rate $I$ and will be used in the policy analysis contained in section 4 of the paper.

Definition II: Normative SAVINGS RATE II IS THE SAVINGS RATE TO WHICH SELF 0 WOULD COMMIT ALL FUTURE SELVES.

Let

$$
\lambda^{I I} \equiv \operatorname{argmax}_{\lambda} \beta \sum_{i=1}^{\infty} \delta^{i} u\left(\lambda(1-\lambda)^{i-1} R^{i} W\right) .
$$

It is straightforward to show that $\lambda^{H}=1-\left(\delta R^{1-\rho}\right)^{\frac{1}{\rho}}$. By definition, normative savings rate II is given by:

$$
S^{I I} \equiv \frac{(R-1)-\lambda^{I} R}{R-1}
$$

Proposition 8: Normative Savings rate II $\left(S^{\prime \prime}\right)$ IS GReater. THAN NORMATIVE SAVINGS RATE I $\left(S^{I}\right)$. IF $\beta$ IS SUFFICIENTLY CLOSE TO ONE, THE CONSUMPTION PATH IMPLIED BY NORmative savings Rate II PAReto-Dominates THE EQUilibRIUM CONSUMPTION PATH. IF $\beta$ IS SUFFICIENTLY CLOSE TO ZERO, THE CONSUMPTION PATH IMPLIED BY NORMATIVE SAVINGS RATE II DOES NOT PARETO-DOMINATE THE EQUILIBRIUM CONSUMPTION PATH.

The benchmark calibration values imply $S^{*}=.133, S^{I}=.241$, and $S^{I I}=.246$. Hence, the gaps between the normative savings rates and the 
actual savings rate are $S^{I}-S^{*}=.108$ and $S^{I I}-S^{*}=.113$. Proposition 7 implies that the consumption path associated with normative savings rate I Pareto-dominates the equilibrium consumption path. Moreover, it is easy to quantitatively confirm that for the benchmark calibration values the consumption path associated with normative savings rate II also Paretodominates the equilibrium consumption path. This is not surprising given the similar values that $S^{I}$ and $S^{I I}$ take for the benchmark calibration.

Bernheim (1994) finds that the median gap between U.S. baby boomers' self-reported "target" savings rate and their "actual" savings rate is ten percentage points. ${ }^{9}$ This reported savings gap matches approximately the savings gap predicted to arise in the calibrated hyperbolic economy. The match resulted from the following procedure. First, I used a priori arguments to fix $\delta=.99, \rho=3$, and $R=\exp \{.04\}$. Then I chose $\beta=.6$ to generate the desired ten percentage point (.10) difference between $S_{E}$ and the two normative savings rates. Finally, note that $\beta=.6$ is consistent with experimental evidence on one-year discount rates (see Ainslie (1992)). Table 3 numerically evaluates the three savings rates $-S^{*}, S^{I}$, and $S^{I I}$-.- for a range of other calibration values.

\footnotetext{
${ }^{9}$ The actual questions that Bernheim analyzes are:

What percentage of your annual household income do you think you should save for retirement? ("Target saving")

What percentage of your annual household income are you now saving for retirement? ("Actual saving")

These questions were posed to 1209 randomly selected individuals between the ages of 29 and 47 .
} 


\section{Public policy}

In this section I propose revenue neutral policy measures that implement the consumption path implied by savings rate $S^{I I}$. I focus on implementation of $S^{I I}$ because of analytical tractibility. Little generality is lost as a result of this focus, given that $S^{I}$ and $S^{I I}$ are almost identical in value over the range of reasonable calibration values.

The consumption path associated with $S^{I I}$ is expressed most naturally in terms of the associated consumption rate $\lambda^{\prime \prime}$. This consumption rate implies, $c_{t}=\lambda^{I I} W$ and $c_{t+1}=\lambda^{I I} R\left(1-\lambda^{I I}\right) W$. Hence, the slope of the consumption path is given by,

$$
\frac{c_{t+1}}{c_{t}}=R\left(1-\lambda^{H}\right)
$$

I seek to implement the consumption path which 1) has slope $R \cdot\left(1-\lambda^{\prime I}\right)$, and 2) is binding with respect to the economy's budget constraint. I'll refer to this as the normative consumption path.

\subsection{Delays}

The normative consumption path can be implemented by requiring that consumers choose their consumption level one-period before the consumption actually takes place. Under this scheme, self $t$ would be bound to a consumption level $c_{t}$ chosen at period $t-1$. However, self $t$ would be free to choose any feasible consumption level for period $t+1$. This scheme would work like a bank account that requires advance notification for withdrawals.

Formally, this set-up is another intra-personal game. The only difference between this game and our original game is that self $t$ chooses consumption 
for period $t+1$ instead of choosing consumption for period $t$. I will refer to this as the Advance Notification Game.

Proposition 9: In the Advance Notification Game, the (UNIQUE) ASYMPTOTIC EQUILIBRIUM CONSUMP'TION RATE IS $\lambda^{I I}$.

\subsection{Interest Subsidies and Penalties}

The normative consumption path can also be implemented by a combined policy that penalizes over-consumption and subsidizes the rate of interest. Any net costs of this policy are assumed to be financed by a non-distortionary tax. Consider the following specific scheme. The government penalizes agents who dissave more than $\lambda W_{t}$, where $\lambda$ is set by the government. Assume that the penalty is equal to $p$ multiplied by the amount of excess dissaving (i.e., dissaving in excess of $\lambda W_{t}$ ). Also assume that consumers face a subsidized interest rate $\hat{R}>R$. The government chooses $\lambda, p$, and $\hat{R}$, to satisfy the following three goals:

G1 The equlibrium consumption path coincides with the normative consumption path.

G2 In equilibrium, $c_{t}=\lambda W_{t}$, implying that the penalty is never invoked on the equilibrium path.

G3 It is impossible to lower $p$ without either raising $\hat{R}$ or violating conditions one and two. 
Condition two implies,

$$
\frac{c_{t+1}}{c_{t}}=\hat{R}(1-\lambda)
$$

Combining this with condition one implies,

$$
\hat{R}(1-\lambda)=R\left(1-\lambda^{I I}\right)
$$

This equality expresses $\lambda$ as a function of $\hat{R}$ (and the two known parameters $R$ and $\lambda^{I I}$.) To evaluate the triplet $\{\lambda, p, \hat{R}\}$ it is therefore sufficient to identify the new parameters $p$ and $\hat{R}$.

The generalized Euler equation can be used to derive the values of $p$ and $\hat{R}$. In the presence of a penalty and a subsidized interest rate the generalized Euler equation for period $t$ becomes:

$$
(1-p) u^{\prime}\left(c_{t}\right)=\beta \sum_{i=1}^{T-t} \delta^{i} \frac{\partial c_{t+i}}{\partial W_{t+i}}\left[\prod_{j=1}^{i-1}\left(1-\frac{\partial c_{t+j}}{\partial W_{t+j}}\right)\right] \hat{R}^{i} u^{\prime}\left(c_{t+i}\right)
$$

Consider the analogous Euler equation for period $t+1$ :

$$
(1-p) u^{\prime}\left(c_{t+1}\right)=\beta \sum_{i=1}^{T-(t+1)} \delta^{i} \frac{\partial c_{t+1+i}}{\partial W_{t+1+i}}\left[\prod_{j=1}^{i-1}\left(1-\frac{\partial c_{t+1+j}}{\partial W_{t+1+j}}\right)\right] \hat{R}^{i} u^{\prime}\left(c_{t+1+i}\right)
$$

Substituting the latter equation into the former yields:

$$
(1-p) u^{\prime}\left(c_{1}\right)=\delta \hat{R} u^{\prime}\left(c_{2}\right)\left[\beta \frac{\partial c_{t+1}}{\partial W_{t+1}}+(1-p)\left(1-\frac{\partial c_{t+1}}{\partial W_{t+1}}\right)\right]
$$

Note that $c_{1}=\lambda W, c_{2}=\lambda(1-\lambda) \hat{R} W, \frac{\partial c_{\ell+1}}{\partial W_{t+1}}=\lambda$, and $\hat{R}(1-\lambda)=R\left(1-\lambda^{I I}\right)$. Proposition 10 follows by substituting these relationships into Equation 25 and simplifying the resulting expression. 
Proposition 10: G1-G3 ARE SATISFIED IF AND ONLY IF $p$ AND $\hat{R}$ ARE CHOSEN TO SATISFY,

$$
\hat{R}-R=\beta^{-1}(1-p-\beta) R \lambda^{I I}
$$

Proposition 10 implies that the interest subsidy is decreasing in $\beta$ and decreasing in $p$. As $\beta$ rises to unity, the self-control problem is mitigated and the magnitude of the required interest subsidy falls. As $p$ rises the penalty alone becomes increasingly sufficient to solve the self-control problem and the magnitude of the required interest subsidy falls.

Assume that the government chooses a penalty of .10 (the current penalty which applies to early withdrawals from most retirement accounts in the U.S.). Then under the benchmark calibration, Proposition 10 implies that to implement the normative consumption path the government needs to select an interest rate subsidy of $\hat{R}-R=.015$.

This combination of penalty and interest subsidy matches the penalty and interest subsidy associated with existing U.S. retirement savings instruments like 401K's, IRA's, and 403B's. ${ }^{10}$ All of these accounts have an explicit 10 percent penalty for early withdrawal, and these accounts generate an implicit interest subsidy of approximately .0175 for a representative U.S. consumer. To see this, consider the following intertemporal consumption transformation

\footnotetext{
${ }^{10}$ Note however that there are important differences between the mechanism proposed in this paper and savings instruments like 401K's. First, the hypothetical savings schemes proposed in this paper have no contribution caps. Second, while withdrawals from 401K's are penalized, failures to deposit an "appropriate" amount into the account in the first place do not generate a penalty. The need to elicit deposits may explain the popularity of programs in which employers match the contributions of their employees.
} 
which uses a tax-deferred retirement account as the investment vehicle. A consumer at time $t$ cuts consumption by $(1-\tau)$ to fund a $401 \mathrm{~K}$ investment of $\$ 1$, assuming that $\tau$ is the marginal tax rate. ${ }^{11}$ At the end of $T$ years, the consumer withdraws the accrued value of that investment, $\exp \{(r+\pi) T\}$, where $\pi$ is the inflation rate. The consumer then pays taxes of $\tau \exp \{(r+$ $\pi) T\}$, and can therefore consume $(1-\tau) \exp \{(r+\pi) T\}$, which has real value $(1-\tau) \exp \{r T\}$. Hence, the real rate of intertemporal transformation is:

$$
\frac{1}{T} \log \left(\frac{(1-\tau) \exp \{r T\}}{(1-\tau)}\right)=r .
$$

By contrast, the real rate of intertemporal transformation when using a nontax-advantaged investment vehicle is:

$$
\frac{1}{T} \log (\exp \{(r+\pi)(1-\tau) T-\pi T\})=r(1-\tau)-\pi \tau
$$

Hence, the implicit interest subsidy is:

$$
r-(r(1-\tau)-\pi \tau)=(r+\pi) \tau
$$

If $\tau=.25, r=.04$, and $\pi=.03$ then the interest subsidy associated with existing tax-deferred savings instruments like 401K's is approximately .0175, close to the optimal subsidy implied by the model, .015.

Of course, other models explain why governments may want to "subsidize" the after-tax return on savings. For example, Chamley (1986) has shown that in an infinite horizon economy the optimal long-run tax rate on capital income is zero. ${ }^{12} \mathrm{My}$ analysis provides an additional reason for increasing the after-tax return on capital. In a general model which subsumes

\footnotetext{
${ }^{11} \mathrm{~A} \$ 1$ investment into a $401 \mathrm{~K}$ plan generates a tax rebate of $\tau$ dollars. Hence, to fund a $\$ 1$ investment, the consumer need only cut consumption by $(1-\tau)$.

${ }^{12}$ Aiyagari (1995) argues that in an economy with incomplete markets, Chamley's results are weakened.
} 
both my arguments and those of Chamley, optimality requires a negative long-run tax rate on capital income (i.e., a capital income subsidy). This suggests that 401K's insufficiently subsidize the return to capital, since they effectively implement a zero tax rate on capital income.

Proposition 10 has two natural corollaries. First, if the government chooses to have no interest subsidy (i.e., $\hat{R}=R$ ), then $p=1-\beta$. Second, if the government, chooses to have no penalty (i.e., $p=0$ ), then $\hat{R}-R=\beta^{-1}(1-\beta) R \lambda^{I I}$. For the benchmark calibration the interest subsidy (in the absence of a penalty) is $\hat{R}-R=.021$. Table 4 evaluates the interest subsidy in the absence of a penalty for a range of calibration values.

\section{Welfare analysis}

In the analysis above I have proposed two normative savings rates, and shown how public policy can (and perhaps partially does in the U.S.) implement these savings rates. In this section I evaluate the welfare benefits of implementing these policies. In the game-theoretic framework adopted in this paper, welfare must be evaluated from the perspective of all selves.

\subsection{A welfare measure}

My thought experiment considers the permanent adoption -a starting at time zero - of one of the revenue-neutral policies described in the previous section. I will refer to this as the intervention scenario. Recall that all of the proposed policies implement the $\lambda^{I I}$ savings rate. Because I assume that the policy begins to take effect at time zero, the equilibrium path which arises in the intervention scenario is equivalent to the consumption path induced 
by fixing the consumption rate of all selves (including self 0 ) to $\lambda^{I I}$.

Let $U_{t}\left(W_{0} \mid\right.$ intervention $)$ represent the utility of self $t$ under the intervention scenario, conditional on time zero wealth $W_{0}$. Let $U_{t}\left(W_{0} \mid\right.$ no intervention $)$ represent the utility of self $t$ under the no intervention scenario, conditional on time zero wealth $W_{0}$. Note that under the no intervention scenario, I assume that the schemes discussed in the previous section will not be implemented by private actors. This market failure arises because the schemes are vulnerable to third party arbitrage: any consumer who is engaged in one of these schemes will have an incentive to use a third party to unwind the scheme or arbitrage against the scheme unless the government explicitly forbids such third party contracting. ${ }^{13}$ If the legal environment is set up to prevent such arbitrage, then I will assume that the government is effectively implementing the scheme. Define $\kappa_{t}$ such that:

$$
U_{t}\left(W_{0} \mid \text { no intervention }\right)=U_{t}\left(W_{0} \cdot\left(1-\kappa_{t}\right) \mid \text { intervention }\right)
$$

Hence, $\kappa_{t}$ represents self $t$ 's willingness to pay (as a percentage of time zero wealth) for the intervention policy.

Corollary to Proposition 8: If $\beta$ Is SUfficiently Close to ONE, THEN $\kappa_{t}>0$ FOR ALL $t$.

Proposition 11: The SEQUENCE $\left\{\kappa_{t}\right\}_{t=0}^{\infty}$ IS MONOTONICALLY STRICTLY INCREASING AND $\lim _{t \rightarrow \infty} \kappa_{t}=1$.

\footnotetext{
${ }^{13}$ If a consumer faces a penalty for early withdrawal from a retirement account, the consumer may borrow from a third party to facilitate immediate consumption thereby escaping the penalty. Likewise, if a consumer has access to a subsidized interest rate, the consumer may borrow from a third party to exploit the subsidy.
} 
Recall that $\kappa_{t}$ is a measure of self $t$ 's welfare gains from intervention. Proposition 11 implies that the welfare gains to self 0 are smaller than the welfare gains to all future selves. Hence, whatever weighting function the social planner uses, the welfare gains from the perspective of the social planner are bounded below by the welfare gains to self 0 . The remainder of this section focuses on this lower bound.

\subsection{Evaluating the lower bound.}

Assume that an individual consumes at rate $\lambda$ and begins life with wealth stock $W$. Then the utility of self 0 is given by

$$
u(\lambda W)+\beta \sum_{i=1}^{\infty} \delta^{i} u\left(\lambda(1-\lambda)^{i} R^{i} W\right) .
$$

Substituting for $u(\cdot)$ and simplifying yields,

$$
\frac{(\lambda W)^{1-\rho}}{1-\rho}\left[1+\beta \frac{\delta R^{1-\rho}(1-\lambda)^{1-\rho}}{1-\delta R^{1-\rho}(1-\lambda)^{1-\rho}}\right] .
$$

This implies that $\kappa_{0}$ is equal to:

$$
\kappa_{0}=1-\left(\frac{\lambda^{I I}}{\lambda^{*}}\right)^{\frac{\rho}{1-\rho}} \frac{1}{\left[\lambda^{I I}+\beta\left(1-\lambda^{I I}\right)\right]^{\frac{1}{1-\rho}}} .
$$

Dividing $\kappa_{0} \cdot W$ by $(R-1) \cdot W$ standardizes the consumer's willingness to pay by representing it as a fraction of current income. For the benchmark case this normalized willingness to pay is quite large: .90 . This implies that

consumers are willing to forego $\frac{9}{10}$ of a year's worth of income to induce the government to undertake the proposed revenue-neutral intervention. Table 5 evaluates $\frac{\kappa_{0}}{R-1}$ for a range of parameter values. 


\section{Conclusion}

Recall the benchmark calibration values: $\rho=3, \beta=.6, \delta=.99$, and $R=\exp \{.04\}$. This paper considered several attributes of this "hyperbolic" economy. A few of these are reviewed here.

1) The slope of the consumption path of this economy is equal to the slope of the consumption path in a parallel economy with identical technology and identical coefficient of relative risk aversion, but with exponential discounting with discount factor .977 . Hence a naive econometrician might mistake the hyperbolic economy for an exponential economy in which consumers have relatively low rate of time preference: $1-.977=.023$.

2) The EIS in the hyperbolic economy is $.233<\frac{1}{3}=\frac{1}{\rho}$. Hence, the hyperbolic economy is consistent with the finding that the EIS is less than the inverse of the coefficient of relative risk aversion.

3) The savings rate in the hyperbolic economy $\left(S^{*}\right)$ is .133 which is approximately 11 percentage points below the target savings rate $\left(S^{I I}\right)$ which is .246. Hence, the hyperbolic economy is roughly consistent with Bernheim's (1994) survey results, which find that there is a ten percentage point gap between actual savings rates and target savings rates.

4) A benevolent government could implement the target consumption path by creating a system which penalized excess consumption and subsidized the return on capital. Specifically, if the penalty were $p=.10$ of the amount of 
excess consumption, then the interest subsidy would need to be $\hat{R}-R=.015$ (assumed to be financed with non-distortionary taxes).

5) A benevolent government could implement the target consumption path by ignoring the penalty altogether, and creating just an interest subsidy: $\hat{R}-R=.021$ (assumed to be financed with non-distortionary taxes).

6) All selves would be willing to pay $\frac{9}{10}$ of one year's income (above and beyond the non-distortionary taxes mentioned above) to induce the government to implement one of the proposed savings schemes. 


\section{Appendix: Proofs and Tables}

Before presenting the proofs, it is useful to establish some notation. Let $H_{t}$ be the set of feasible histories of the consumption game at time $t$. An $h_{t} \in H_{t}$ history is a $t+1$-element vector, $\left(W_{0}, c_{0}, c_{1}, c_{2}, \ldots, c_{t-1}\right) \in \Re^{t}$. Let $H_{t}^{F}$ represent the set of feasible histories at time $t$. Let $H^{F}$ be the set of all feasible histories. Let $W: H^{F} \rightarrow[0, \infty)$ be the map from feasible histories to asset stocks, such that $W\left(W_{0}, c_{0}, c_{1}, c_{2}, \ldots, c_{t-1}\right) \equiv R^{t} W_{0}-\sum_{i=0}^{t-1} R^{t-i} c_{i}$. Hence, $W\left(h_{t}\right)$ is wealth available to self $t$ after history $h_{t}$. Represent the pure strategy space of self $t$ as,

$$
S_{t} \equiv\left\{s_{t} \mid s_{t}: H_{t}^{F} \rightarrow[0, \infty), \text { and } 0 \leq s\left(h_{t}\right) \leq W\left(h_{t}\right) \forall h_{t} \in H_{t}^{F}\right\}
$$

Define the joint strategy space $S \equiv \prod_{t=0}^{\infty} S_{t}$. Let $S^{P}$ represent the set of subgame-perfect equilibria of the consumption game. Finally, let $v\left(s, t, h_{i}\right)$ represent the continuation payoff of self $t$, after history $h_{\hat{t}}$, when strategy $s$ is played from time $\hat{t}$ forward.

Proof of Proposition 1: Let $s_{t}^{T}$ be a point in the strategy space of self $t$ in a game with horizon $T$. So $s_{t}^{T}: H_{t}^{F} \rightarrow[0, \infty)$. Suppose that the T-horizon game has a unique perfect equilibrium. Also suppose that this equilibrium has strategies of the form: $s_{t}^{T}\left(h_{t}\right)=\lambda_{T^{\prime}-t} W_{t}$, for all selves $t \in\{0,1, \ldots, T\}$. Finally, assume $0<\lambda_{T-t}<1$ for all $t \in\{0,1,2, \ldots, T-1\}$. Let $V(A, T+1) \equiv$ $\beta \delta \sum_{t=0}^{T} \delta^{t} u\left(\lambda_{T-t} W_{t}\right)$, where $W_{0}=A$, and the rest of the $W_{t}$ sequence is built up recursively: $W_{t+1}=R\left(1-\lambda_{T^{\prime}-t}\right) W_{t}$. It is easy to show $V_{A}(A, T+1)>0$ and $V_{A A}(A, T+1)<0 \forall A \in(0, \infty)$, and $\lim _{A \rightarrow 0} V_{A}(A, T+1)=\infty$. Now consider 
the behavior of self 0 in a game with horizon $T+1$. Since there is a unique subgame perfect equilibrium in the subgame that arises after self 0's choice, self 0 chooses a consumption level to maximize, $u\left(c_{0}\right)+V\left(R\left(W_{0}-c_{0}\right), T+1\right)$, subject to the restriction $0 \leq c_{0} \leq W_{0}$. The properties of $u(\cdot)$ and $V(\cdot, T+1)$ imply that this problem has a unique interior solution. It is easy to show that the chosen consumption level is proportional to, but less than, $W_{0}$. Hence, there exists a number $\lambda, 0<\lambda<1$ such that $c_{0}=\lambda W_{0} \forall W_{0}$. Set $\lambda_{T+1} \equiv \lambda$. The proof proceeds by induction. To start the induction, simply observe that $\lambda_{0}=1$.

Proof of Proposition 2: Continuing the argument from the proof of Proposition 2 , note that in equilibrium the following condition holds for all $t$ :

$$
u^{\prime}\left(c_{t}\right)=R V_{A}\left(W_{t+1}, T-t\right)
$$

Note that $V\left(W_{t+1}, T-t\right)$ can be reexpressed, $V\left(W_{t+1}, T-t\right)=$

$$
\beta \delta u\left(c_{t+1}\left(W_{t+1}, T\right)\right)+\delta V\left(R\left(W_{t+1}-c_{t+1}\left(W_{t+1}, T\right)\right), T-(t+1)\right)
$$

Taking a partial derivative, yields, $V_{A}\left(W_{t+1}, T-t\right)=$

$$
\beta \delta u^{\prime}\left(c_{t+1}\right) \frac{\partial c_{t+1}}{\partial W_{t+1}}+\delta R V_{A}\left(R\left(W_{t+1}-c_{t+1}\right), T-(t+1)\right)\left[1-\frac{\partial c_{t+1}}{\partial W_{t+1}}\right]
$$

Finally substitute $u^{\prime}\left(c_{t+1}\right)$ for $R V_{A}\left(W_{t+2}, T-(t+1)\right)$ to get the required result.

Proof of Propositions 3 and 4: Recall that the proof of Proposition 1 shows that in a game with horizon $T$, the unique perfect equilibrium strategy 
of self $t$ is to consume at rate $\lambda_{T-t}$. Given this observation, it is possible to use Proposition 2 to characterize the consumption of self $t$ in a $T+1$-horizon game.

Note that Proposition 2 implies that the following equation holds on the unique equilibrium path of any finite horizon subgame:

$$
u^{\prime}\left(c_{t-1}\right)=R \delta u^{\prime}\left(c_{t}\right)\left[\frac{\partial c_{t}\left(W_{t}, T\right)}{\partial W_{t}}(\beta-1)+1\right]
$$

Assume that the game has horizon $T$. Substitute in for $u(\cdot)$, replace $c_{t}$ with $\lambda_{T-t} W_{t}$, and replace the partial derivative with $\lambda_{T-t}$. Solving for $c_{t-1}$ yields,

$$
c_{t-1}=\lambda_{T-(t-1)} W_{t-1}
$$

where

$$
\lambda_{T-(t-1)}=\frac{\lambda_{T-t}}{\left[\delta R^{1-\rho}\left(\lambda_{T-t}(\beta-1)+1\right)\right]^{\frac{1}{\rho}}+\lambda_{T-t}}
$$

This implies that in a finite horizon game it is possible to calculate the equilibrium consumption rate of today's self from the equilibrium consumption rate of tomorrow's self. Another way of thinking about this is to say that it is possible to calculate self $t$ 's equilibrium strategy in the $T+1$-horizon game if we know self $t$ 's equilibrium strategy in the $T$-horizon game.

So far I've noted the following properties. First $c_{t}\left(W_{t}, T\right)=\lambda_{T^{\prime} t} W_{t}$ both on and off the equilibrium path. Second, the sequence of consumption rates $\left\{\lambda_{r}\right\}_{r=0}^{\infty}$, follows the recursion,

$$
\lambda_{r+1}=f\left(\lambda_{r}\right) \equiv \frac{\lambda_{r}}{\left[\delta R^{1-\rho}\left(\lambda_{r}(\beta-1)+1\right)\right]^{\frac{1}{\rho}}+\lambda_{r}}
$$

Hence, to prove the Theorem it is sufficient to show that $\lambda_{r} \rightarrow \lambda^{*}$. 
In the argument which follows I'll use the following properties of $f(\cdot)$, which are straightforward to confirm.

- $f(0)=0$.

- $f(\cdot)$ differentiable on $[0,1]$.

- $f^{\prime}(0)>1$ (using technology assumption $\delta R^{(1-\rho)}<1$ ).

- $f^{\prime}(x)>0$ on $[0,1]$.

- $f(1)<1$.

Let $\bar{\lambda}=\sup \{\lambda \mid \lambda \in[0,1], \lambda=f(\lambda)\}$. There is at least one fixed point at zero, so $\bar{\lambda}$ exists. In fact, it is possible to show that $\bar{\lambda}$ is strictly greater than zero. This follows from the properties $f(0)=0, f^{\prime}(0)>1, f(\cdot)$ continuous, $f(1)<1$, and by application of the Intermediate Value Theorem. Finally, $\lambda_{r} \rightarrow \bar{\lambda}$ since $f^{\prime}(x)>0$ on $[0,1], f(1)<1$, and $\lambda_{0}=1$.

It only remains to show that $\bar{\lambda}=\lambda^{*}$. Recall that $\bar{\lambda}=f(\bar{\lambda})$. Both sides of this equation can be divided by $\bar{\lambda}$ since it has been shown that $\bar{\lambda}>0$. Transforming the resulting equality it is easy to show that

$$
\bar{\lambda}=1-\left(\delta R^{1-\rho}\right)^{\frac{1}{\rho}}[\bar{\lambda}(\beta-1)+1]^{\frac{1}{\rho}} .
$$

This equation has a unique solution.

Proof of Proposition 5: See text.

Proof of Proposition 6: If $\rho>1$, then

$$
\lim _{\beta \rightarrow 0} \lambda^{*}=1-\left(\delta R^{1-\rho}\right)^{\frac{1}{\rho-1}}<1 .
$$


This result follows from Equation 9. Now, recall Equation 15.

$$
\frac{\partial \log \left(\frac{c_{t+1}}{c_{t}}\right)}{\partial r}=\frac{1}{\rho}+\frac{1}{\rho}\left[\frac{(1-\rho)\left(1-\lambda^{*}\right)}{-(\beta-1)\left(1-\lambda^{*}\right)-\rho\left(\lambda^{*}(\beta-1)+1\right)}\right](\beta-1) .
$$

Since $\lim _{\beta \rightarrow 0}\left(1-\lambda^{*}\right)=\left(\delta R^{1-\rho}\right)^{\frac{1}{\rho-1}}$, the numerator and the denominator of the bracketed term in Equation 15 both have finite, non-zero limits. Hence,

$$
\lim _{\beta \rightarrow 0} \frac{\partial \log \left(\frac{c_{t+1}}{c_{t}}\right)}{\partial r}=\frac{1}{\rho}+\frac{1}{\rho}\left[\frac{(1-\rho)\left(\delta R^{1-\rho}\right)^{\frac{1}{\rho-1}}}{\left(\delta R^{1-\rho}\right)^{\frac{1}{\rho-1}}-\rho\left(\delta R^{1-\rho}\right)^{\frac{1}{\rho-1}}}\right](-1),
$$

which simplifies to the required result.

Proof of Proposition 7: Let

$$
f(\lambda) \equiv u(\lambda)+\beta \sum_{i=1}^{\infty} \delta^{i} u\left(\lambda(1-\lambda)^{i} R^{i}\right)
$$

and let

$$
g(\lambda) \equiv u(\lambda)+\sum_{i=1}^{\infty} \delta^{i} u\left(\lambda(1-\lambda)^{i} R^{i}\right)
$$

Since, $u(x)=\frac{x^{1-\rho}}{1-\rho}, f(\lambda)$ can be represented,

$$
f(\lambda)=u(\lambda)+\beta \delta R^{1-\rho}(1-\lambda)^{1-\rho} g(\lambda) .
$$

The first step in the proof of Proposition 7 is to show $g^{\prime}(\lambda)<0$ for all $\lambda$ such that $\lambda^{*} \leq \lambda<\bar{\lambda}$ where $\bar{\lambda}=\sup \{\lambda \mid g(\lambda)>-\infty\}$. To sign this derivative over this domain it is helpful to note the following properties of $g(\cdot)$. First, $g(\cdot)$ has a unique local (and hence global) maximum at $\lambda=1-\left(\delta R^{1-\rho}\right)^{\frac{1}{\rho}}$. Second, since $g(\cdot)$ is differentiable, $g^{\prime}(\lambda)<0$ if $1-\left(\delta R^{1-\rho}\right)^{\frac{1}{\rho}}<\lambda<\bar{\lambda}$. Third, $1-\left(\delta R^{1-\rho}\right)^{\frac{1}{\rho}}<\lambda^{*}$. (This third point is shown by noting: (a) the partial derivative of the RHS of Equation 9 with respect to $\lambda$ is less than one; (b) 
evaluating the RHS of Equation 9 at $\lambda=1-\left(\delta R^{1-\rho}\right)^{\frac{1}{\rho}}$ yields a value which is greater than $1-\left(\delta R^{1-\rho}\right)^{\frac{1}{\rho}}$.) Combining observations yields, $g^{\prime}(\lambda)<0$ if $\lambda^{*}<\lambda<\bar{\lambda}$.

The next step in the proof of Proposition 7 is to show

$$
u^{\prime}(\lambda)-(1-\rho) \beta \delta R^{1-\rho}(1-\lambda)^{-\rho} g(\lambda)<0
$$

if $\lambda^{*}<\lambda<\bar{\lambda}$. First, note that $u^{\prime}(\lambda)-(1-\rho) \beta \delta R^{1-\rho}(1-\lambda)^{-\rho} g(\lambda)=0$ iff $\lambda=$ $\lambda^{*}$. (This first point is shown by noting: (a) $\lambda^{*}$ is the unique linear symmetric Markov equilibrium in the infinite-horizon game (Phelps and Pollak (1968)); (b) $u^{\prime \prime}(\lambda)-\rho(1-\rho) \beta \delta R^{1-\rho}(1-\lambda)^{-\rho-1} g(x)<0$, for all $\lambda, x$; (c) the concavity property stated in b) implies, $u^{\prime}(\lambda)-(1-\rho) \beta \delta R^{1-\rho}(1-\lambda)^{-\rho} g(\lambda)=0$ iff $\lambda$ supports a linear symmetric Markov equilibrium.) Second, note that $u^{\prime}(\lambda)-$ $(1-\rho) \beta \delta R^{1-\rho}(1-\lambda)^{-\rho} g(\lambda)<0$ if $\lambda^{*}<\lambda<\bar{\lambda}$. (This second point is shown by noting $\lim _{\lambda \rightarrow \bar{\lambda}} u^{\prime}(\lambda)-(1-\rho) \beta \delta R^{1-\rho}(1-\lambda)^{-\rho} g(\lambda)<0$. Application of the Intermediate Value Theorem implies that $u^{\prime}(\lambda)-(1-\rho) \beta \delta R^{1-\rho}(1-\lambda)^{-\rho} g(\lambda)$ can take on a positive value somewhere in the interval $\left(\lambda^{*}, \bar{\lambda}\right)$ only if $u^{\prime}(\lambda)-$ $(1-\rho) \beta \delta R^{1-\rho}(1-\lambda)^{-\rho} g(\lambda)=0$ at some point in that interval. But, this has already been ruled out.)

Combining results yields,

$$
f^{\prime}(\lambda)=u^{\prime}(\lambda)-(1-\rho) \beta \delta R^{1-\rho}(1-\lambda)^{-\rho} g(\lambda)+\beta \delta R^{1-\rho}(1-\lambda)^{1-\rho} g^{\prime}(\lambda)<0
$$

if $\lambda^{*} \leq \lambda<\bar{\lambda}$. This demonstrates $\lambda^{I}<\lambda^{*}$. Pareto-dominance follows from the fact that all future selves are made better off in two ways. First they prefer the sequence of low $\lambda$ values that applies to their current and future consumption choices, and second they prefer inheriting greater levels of wealth as implied by the sequence of previous low $\lambda$ values. 
Proof of Proposition 8: Using the implicit function theorem it is possible to show that equation 18 implies,

$$
\frac{\partial \lambda}{\partial \beta}<0
$$

Also note that when $\beta=1$ equation 18 implies,

$$
\lambda=1-\left(\delta R^{1-\rho}\right)^{\frac{1}{\rho}}
$$

This is sufficient to show that normative savings rate I is less than normative savings rate II.

To show the Pareto-dominance result, I introduce the following notation. Let $U(\lambda)$ represent the utility of self 0 , given that all selves (including self 0 ) consume at rate $\lambda$. I seek to show $f(\beta) \equiv U\left(\lambda^{I I}\right)-U\left(\lambda^{*}(\beta)\right)>0$ when $\beta$ is close to unity. This notation is used to emphasize that $U\left(\lambda^{*}(\beta)\right)$ depends on $\beta$ in two ways. First, $\beta$ is a discount rate, so changes in $\beta$ affect the value of future consumption. Second, $\beta$ is in the implicit equation which determines $\lambda^{*}$. Note that $\beta$ only influences $U\left(\lambda^{I I}\right)$ through the former mechanism as $\lambda^{I I}$ does not depend on $\beta$.

The body of this proof characterizes the value of $f(\cdot)$ in a neighborhood of $\beta=1$. First, $f(1)=0$ since $\lambda^{*}(1)=\lambda^{I I}$. To evaluate $f(\cdot)$ at $\beta$ values just below unity, I consider $f^{\prime}(1)$ and $f^{\prime \prime}(1)$.

$$
f^{\prime}(\beta)=\frac{\partial U\left(\lambda^{I I}\right)}{\partial \beta}-\frac{\partial U\left(\lambda^{*}\right)}{\partial \beta}-\frac{\partial U\left(\lambda^{*}\right)}{\partial \lambda^{*}} \frac{d \lambda^{*}}{d \beta}
$$

Note that $f^{\prime}(1)=0$, as $\left.\frac{\partial U\left(\lambda^{I I}\right)}{\partial \beta}\right|_{\beta=1}=\left.\frac{\partial U\left(\lambda^{*}\right)}{\partial \beta}\right|_{\beta=1}$, and, $\left.\frac{\partial U\left(\lambda^{*}\right)}{\partial \lambda^{*}}\right|_{\beta=1}=\left.\frac{\partial U\left(\lambda^{I I}\right)}{\partial \lambda^{I I}}\right|_{\beta=1}=$ 0 . Tedious algebraic manipulations reveal that

$$
f^{\prime \prime}(1)=\frac{1}{\rho}\left(\lambda^{I I}\right)^{-\rho}\left(1-\lambda^{I I}\right)\left(1-2 \lambda^{I I}\right)
$$


which is positive by (recall that $\left.\lambda^{I I}=1-\left(\delta R^{1-\rho}\right)^{1 / \rho}\right)$. Given that $f(1)=0$, $f^{\prime}(1)=0$, and $f^{\prime \prime}(1)>0$, there exists an interval $(\underline{\beta}, 1)$ such that $f(\beta)>0$ $\forall \beta \in(\underline{\beta}, 1)$. Hence, for sufficiently large $\beta<1, f(\beta)$ is positive. This shows that self 0 is made better off by switching to the $\lambda^{I I}$ path. Pareto-dominance follows from the fact that all future selves are made better off in two ways. First they prefer the sequence of $\lambda^{I I}$ values that applies to their current and future consumption choices, and second they prefer inheriting greater levels of wealth as implied by the sequence of past $\lambda^{I I}$ values.

Proof of Proposition 9: Apply analogous arguments to the arguments used to prove Propositions 1-4. First, let $s_{t}^{T}$ be a point in the strategy space of self $t$ in a game with horizon $T$. So $s_{t}^{T}: H_{t+1}^{F} \rightarrow[0, \infty)$. Suppose that the T-horizon game has a unique perfect equilibrium. Also suppose that this equilibrium has strategies of the form: $s_{t}^{T}\left(h_{t}\right)=\lambda_{T-(t+1)} W_{t+1}$, for all selves $t \in\{0,1, \ldots, T-1\}$. Finally, assume $0<\lambda_{T-(t+1)}<1$ for all $t \in$ $\{0,1,2, \ldots, T-2\}$. Let $V(A, T+1) \equiv \beta \delta \sum_{t=1}^{T} \delta^{t} u\left(\lambda_{T-t} W_{t}\right)$, where $W_{1}=A$, and the rest of the $W_{t}$ sequence is built up recursively: $W_{t+1}=R\left(1-\lambda_{T-1}\right) W_{t}$. It is easy to show $V_{A}(A, T+1)>0$ and $V_{A A}(A, T+1)<0 \forall A \in(0, \infty)$, and $\lim _{A \rightarrow 0} V_{A}(A, T+1)=\infty$. Now consider the behavior of self 0 in a game with horizon $T+1$. Since there is a unique subgame perfect equilibrium in the subgame that arises after self 0's choice, self 0 chooses a consumption level to maximize, $\beta \delta u\left(c_{1}\right)+V\left(R\left(W_{1}-c_{1}\right), T+1\right)$, subject to the restriction $0 \leq c_{1} \leq W_{1}$. The properties of $u(\cdot)$ and $V(\cdot, T+1)$ imply that this problem has a unique interior solution. It is easy to show that the chosen consumption level is proportional to, but less than, $W_{1}$. Hence, there exists a number $\lambda$, 
$0<\lambda<1$ such that $c_{1}=\lambda W_{1} \forall W_{1}$. Set $\lambda_{T} \equiv \lambda$. The proof proceeds by induction. To start the induction, simply observe that $\lambda_{0}=1$. $\square$ Note that in equilibrium the following condition holds for all $t$ :

$$
\beta \delta u^{\prime}\left(c_{t}\right)=R V_{A}\left(W_{t+1}, T-t\right)
$$

Note that $V\left(W_{t+1}, T-t\right)$ can be reexpressed, $V\left(W_{t+1}, T-t\right)=$

$$
\beta \delta^{2} u\left(c_{t+1}\left(W_{t+1}, T\right)\right)+\delta V\left(R\left(W_{t+1}-c_{t+1}\left(W_{t+1}, T\right)\right), T-(t+1)\right)
$$

Taking a partial derivative, yields, $V_{A}\left(W_{t+1}, T-t\right)=$

$$
\beta \delta^{2} u^{\prime}\left(c_{t+1}\right) \frac{\partial c_{t+1}}{\partial W_{t+1}}+\delta R V_{A}\left(R\left(W_{t+1}-c_{t+1}\right), T-(t+1)\right)\left[1-\frac{\partial c_{t+1}}{\partial W_{t+1}}\right]
$$

Finally substitute $\beta \delta u^{\prime}\left(c_{t+1}\right)$ for $R V_{A}\left(W_{t+2}, T-(t+1)\right)$ to find:

$$
u^{\prime}\left(c_{t}\right)=\delta R u^{\prime}\left(c_{t+1}\right)
$$

Substitute in for $u(\cdot)$, replace $c_{t}$ with $\lambda_{T-t} W_{t}$, and replace the partial derivative with $\lambda_{T-t}$. Solving for $c_{t-1}$ yields,

$$
c_{t-1}=\lambda_{T-(t-1)} W_{t-1}
$$

where

$$
\lambda_{T-(t-1)}=\frac{\lambda_{T-t}}{\left[\delta R^{1-\rho}\right]^{\frac{1}{\rho}}+\lambda_{T-t}}
$$

Using the same types of arguments introduced in the proof of Propositions $3-4$, it can be shown that $\lim _{t \rightarrow \infty} \lambda_{T-t}=1-\left(\delta R^{1-\rho}\right)^{\frac{1}{\rho}}$.

Proof of Proposition 10: See text. 
Proof of Proposition 11: By Equation 29, $U_{t}\left(W_{0} \mid\right.$ no intervention $)=$

$$
\frac{\left(\lambda W_{0}\left(1-\lambda^{*}\right)^{t} R^{t}\right)^{1-\rho}}{1-\rho}\left[1+\beta \frac{\delta R^{1-\rho}\left(1-\lambda^{*}\right)^{1-\rho}}{1-\delta R^{1-\rho}\left(1-\lambda^{*}\right)^{1-\rho}}\right],
$$

and $U_{t}\left(W_{0}\left(1-\kappa_{t}\right) \mid\right.$ intervention $)=$

$$
\frac{\left(\lambda W_{0}\left(1-\kappa_{t}\right)\left(1-\lambda^{I I}\right)^{t} R^{t}\right)^{1-\rho}}{1-\rho}\left[1+\beta \frac{\delta R^{1-\rho}\left(1-\lambda^{I I}\right)^{1-\rho}}{1-\delta R^{1-\rho}\left(1-\lambda^{I I}\right)^{1-\rho}}\right] .
$$

To solve for $\kappa_{t}$ set

$$
U_{t}\left(W_{0} \mid \text { no intervention }\right)=U_{t}\left(W_{0}\left(1-\kappa_{t}\right) \mid \text { intervention }\right)
$$

To solve for $\kappa_{t+1}$ set

$$
U_{t+1}\left(W_{0} \mid \text { no intervention }\right)=U_{t+1}\left(W_{0}\left(1-\kappa_{t+1}\right) \mid \text { intervention }\right)
$$

Dividing this last equation by the previous one, yields,

$$
\frac{\left(1-\lambda^{*}\right)}{\left(1-\lambda^{I I}\right)}=\frac{\left(1-\kappa_{t}\right)}{\left(1-\kappa_{t+1}\right)}
$$

Since, $\lambda^{*}<\lambda^{I I}$ (Proposition 8), $\kappa_{t}<\kappa_{t+1}$. 
Table 1: Values of $\bar{\delta}$

Panel A: $\rho=1$.

\begin{tabular}{||l||c|c|c|c||}
\hline & $\beta=.25$ & $\beta=.50$ & $\beta=.75$ & $\beta=1.00$ \\
\hline \hline$\delta=.95$ & .826 & .905 & .934 & .950 \\
\hline$\delta=.97$ & .890 & .942 & .960 & .970 \\
\hline$\delta=.99$ & .961 & .980 & .987 & .990 \\
\hline
\end{tabular}

Panel B: $\rho=3$.

\begin{tabular}{||l||c|c|c|c||}
\hline & $\beta=.25$ & $\beta=.50$ & $\beta=.75$ & $\beta=1.00$ \\
\hline \hline$\delta=.95$ & .910 & .926 & .939 & .950 \\
\hline$\delta=.97$ & .935 & .949 & .960 & .970 \\
\hline$\delta=.99$ & .961 & .973 & .982 & .990 \\
\hline
\end{tabular}

Panel C: $\rho=5$.

\begin{tabular}{||c||c|c|c|c||}
\hline & $\beta=.25$ & $\beta=.50$ & $\beta=.75$ & $\beta=1.00$ \\
\hline \hline$\delta=.95$ & .916 & .928 & .940 & .950 \\
\hline$\delta=.97$ & .938 & .950 & .960 & .970 \\
\hline$\delta=.99$ & .961 & .972 & .981 & .990 \\
\hline
\end{tabular}


Table 2: Elasticity of Intertemporal Substitution

Panel A: $\rho=3$.

\begin{tabular}{||l||c|c|c|c||}
\hline & $\beta=.25$ & $\beta=.50$ & $\beta=.75$ & $\beta=1.00$ \\
\hline \hline$\delta=.95$ & .116 & .204 & .275 & .333 \\
\hline$\delta=.97$ & .115 & .204 & .275 & .333 \\
\hline$\delta=.99$ & .114 & .203 & .274 & .333 \\
\hline
\end{tabular}

Panel B: $\rho=5$.

\begin{tabular}{||c||c|c|c|c||}
\hline & $\beta=.25$ & $\beta=.50$ & $\beta=.75$ & $\beta=1.00$ \\
\hline \hline$\delta=.95$ & .061 & .114 & .159 & .200 \\
\hline$\delta=.97$ & .061 & .113 & .159 & .200 \\
\hline$\delta=.99$ & .061 & .113 & .159 & .200 \\
\hline
\end{tabular}


Table 3: $S_{E}, S_{I}, S_{I I}$.

Panel A: $\rho=1$

\begin{tabular}{||c||c|c|c|c||}
\hline & $\beta=.25$ & $\beta=.50$ & $\beta=.75$ & $\beta=1.00$ \\
\hline \hline$\delta=.95$ & $-3.44,-.46,-.28$ & $-1.43,-.34,-.28$ & $-.67,-.30,-.28$ & $-.28,-.28,-.28$ \\
\hline$\delta=.97$ & $-1.81, .17, .23$ & $-.49, .21, .23$ & $-.01, .23, .23$ & $.23, .23, .23$ \\
\hline$\delta=.99$ & $.01, .74, .74$ & $.50, .74, .74$ & $.66, .74, .74$ & $.74, .74, .74$ \\
\hline
\end{tabular}

Panel B: $\rho=3$

\begin{tabular}{||c||c|c|c|c||}
\hline & $\beta=.25$ & $\beta=.50$ & $\beta=.75$ & $\beta=1.00$ \\
\hline \hline$\delta=.95$ & $-.44,-.13,-.09$ & $-.30,-.11,-.09$ & $-.19,-.10,-.09$ & $-.09,-.09,-.09$ \\
\hline$\delta=.97$ & $-.22, .05, .08$ & $-.10, .07, .08$ & $-.00, .07, .08$ & $.08, .08, .08$ \\
\hline$\delta=.99$ & $.00, .23, .25$ & $.10, .24, .25$ & $.18, .24, .25$ & $.25, .25, .25$ \\
\hline
\end{tabular}

Panel C: $\rho=5$

\begin{tabular}{||c||c|c|c|c||}
\hline & $\beta=.25$ & $\beta=.50$ & $\beta=.75$ & $\beta=1.00$ \\
\hline \hline$\delta=.95$ & $-.24,-.08,-.06$ & $-.17,-.06,-.06$ & $-.11,-.06,-.06$ & $-.06,-.06,-.06$ \\
\hline$\delta=.97$ & $-.12, .03, .05$ & $-.06, .04,05$ & $-.00, .04, .05$ & $.05, .05, .05$ \\
\hline$\delta=.99$ & $.00, .13, .15$ & $.06, .14, .15$ & $.10, .15, .15$ & $.15, .15, .15$ \\
\hline
\end{tabular}


Table 4: $\hat{R}-R$.

Panel A: $\rho=1$

\begin{tabular}{||c||c|c|c|c||}
\hline & $\beta=.25$ & $\beta=.50$ & $\beta=.75$ & $\beta=1.00$ \\
\hline \hline$\delta=.95$ & .156 & .052 & .017 & 0 \\
\hline$\delta=.97$ & .094 & .031 & .010 & 0 \\
\hline$\delta=.99$ & .031 & .010 & .003 & 0 \\
\hline
\end{tabular}

Panel B: $\rho=3$

\begin{tabular}{||l||c|c|c|c||}
\hline & $\beta=.25$ & $\beta=.50$ & $\beta=.75$ & $\beta=1.00$ \\
\hline \hline$\delta=.95$ & .134 & .045 & .015 & 0 \\
\hline$\delta=.97$ & .113 & .038 & .013 & 0 \\
\hline$\delta=.99$ & .092 & .031 & .010 & 0 \\
\hline
\end{tabular}

Panel C: $\rho=5$

\begin{tabular}{||l||c|c|c|c||}
\hline & $\beta=.25$ & $\beta=.50$ & $\beta=.75$ & $\beta=1.00$ \\
\hline \hline$\delta=.95$ & .129 & .043 & .014 & 0 \\
\hline$\delta=.97$ & .117 & .039 & .013 & 0 \\
\hline$\delta=.99$ & .104 & .035 & .012 & 0 \\
\hline
\end{tabular}


Table 5: $\frac{\kappa_{0}}{R-1}$

Panel A: $\rho=1$

\begin{tabular}{||c||c|c|c|c||}
\hline & $\beta=.25$ & $\beta=.50$ & $\beta=.75$ & $\beta=1.00$ \\
\hline \hline$\delta=.95$ & 6.45 & 2.88 & 0.70 & 0 \\
\hline$\delta=.97$ & 7.10 & 3.12 & 0.75 & 0 \\
\hline$\delta=.99$ & 7.78 & 3.36 & 0.80 & 0 \\
\hline
\end{tabular}

Panel B: $\rho=3$

\begin{tabular}{||l||c|c|c|c||}
\hline & $\beta=.25$ & $\beta=.50$ & $\beta=.75$ & $\beta=1.00$ \\
\hline \hline$\delta=.95$ & 4.78 & 1.51 & 0.32 & 0 \\
\hline$\delta=.97$ & 4.89 & 1.54 & 0.31 & 0 \\
\hline$\delta=.99$ & 4.99 & 1.57 & 0.27 & 0 \\
\hline
\end{tabular}

Panel C: $\rho=5$

\begin{tabular}{||l||c|c|c|c||}
\hline & $\beta=.25$ & $\beta=.50$ & $\beta=.75$ & $\beta=1.00$ \\
\hline \hline$\delta=.95$ & 2.80 & 0.87 & 0.15 & 0 \\
\hline$\delta=.97$ & 2.81 & 0.87 & 0.15 & 0 \\
\hline$\delta=.99$ & 2.86 & 0.93 & 0.21 & 0 \\
\hline
\end{tabular}




\section{References}

Ainslie, George W. (1975) "Specious Reward: A Behavioral Theory of Impulsiveness and Impulsive Control." Psychological Bulletin, 82, 463-96.

Ainslie, George W. (1986) "Beyond Microeconomics. Conflict Among Interests in a Multiple Self as a Determinant of Value." in Jon Elster, ed., The Multiple Self, Cambridge: Cambridge University Press, 133-175.

Ainslie, George W. (1992) Picoeconomics, Cambridge: Cambridge University Press.

Aiyagari, S. Rao. (1995) "Optimal Capital Income Taxation with Incomplete Markets, Boprrowing Constraints, and Constant Discounting," Journal of Political Economy, 103 (6), pp. 1158-1175.

Akerlof, George A. (1991) "Procrastination and Obedience." American Economic Review, AEA Papers and Proceedings, 1-19.

Barsky, Robert B., F. Thomas Juster, Miles S. Kimball, Matthew D. Shapiro (1995) "Preference Parameters and Behavioral Heterogeneity: An Experimental Approach in the Health and Retirement Survey," NBER. working paper.

Bernheim, B. Douglas. (1994) "Do Households Appreciate their Financial Vulnerabilites? An Analysis of Actions, Perceptions, and Public Policy." Mimeo, Princeton University. 
Carroll, Christopher D. and Lawrence H. Summers. (1991) "Consumption Growth Parallels Income Growth: Some New Evidence," in B. Douglas Bernheim and John B. Shoven eds., National Saving and Economic Performance, Chicago: Chicago University Press for NBER, 1991, 30543.

Chamley, Christophe. (1986) "Optimal Taxation of Capital Income in General Equilibrium with Infinite Lives." Econometrica 54: 607-622.

Chung, Shin-Ho and Richard J. Herrnstein. (1961) "Relative and Absolute Strengths of Response as a Function of Frequency of Reinforcement." Journal of the Experimental Analysis of Animal Behavior, 4, 267-72.

DeVilliers, P., and Richard J. Herrnstein (1976) "Toward a Law of Response Strength." Psychological Bulletin, 83, 1131-53.

Fudenberg, Drew and Jean Tirole (1991) Game Theory, Cambridge: MIT Press.

Goldman, Steven M. (1980) "Consistent Plans." Review of Economic Studies, 47, 533-37.

Hall, Robert E. (1988) "Intertemporal Substitution in Consumption." Journal of Political Economy, 96, 339-357.

Hubbard, Glenn R., Jonathan Skinner, Steve Zeldes. (1995) "Precautionary Saving and Social Insurance." Journal of Political Economy, 103, 360399 . 
Laibson, David I. (1993a) "Golden Eggs and Hyperbolic Discounting." MIT mimeo.

Laibson, David I. (1993b) "Mental Accounts, Self-Control, and an Intrapersonal Principal-Agent Problem." MIT mimeo.

Loewenstein, George, and Drazen Prelec. (1992) "Anomalies in Intertemporal Choice: Evidence and an Interpretation." Quarterly Journal of Economics, 57:2, 573-598.

Mankiw, N. Gregory and Stephen P. Zeldes. (1991) "The Consumption of Stockholders and Nonstockholders." Journal of Financial Economics, 29, $97-112$.

Peleg, Bezalel, and Menahem E. Yaari. (1973) "On the Existence of a Consistent Course of Action when Tastes are Changing," Review of Economic Studies, 40, 391-401.

Phelps, E. S., and R. A. Pollak. (1968) "On Second-best National Saving and Game-equilibrium Growth." Review of Economic Studies, 35, 185199.

Pollak, R. A. (1968) "Consistent Planning." Review of Economic Studies, $35,201-208$.

Prelec, Drazen. (1989) "Decreasing Impatience: Definition and Consequences." Harvard Business School Working Paper.

Schelling, Thomas C. (1984) "Self-Command in Practice, in Policy, and in 
a Theory of Rational Choice," AEA Papers and Proceedings. 74 (2), pp. 1-11.

Strotz, Robert H. (1956) "Myopia and Inconsistency in Dynamic Utility Maximization." Review of Economic Studies, 23, 165-180.

Thaler, Richard H., and H. M. Shefrin, (1981) "An Economic Theory of Self-Control," Journal of Political Economy, 89 (2), pp. 392-406.

Zeckhauser, Richard and Stephen Fels (1968) "Discounting for proximity with perfect and total altruism," Harvard Institute of Economic Research, Discussion paper 50. 